\title{
INTERVENCIÓN EN LA AROUITECTURA Y BIENES MUEBLES PATRIMONIALES DE LA BASÍLICA DE SAN FRANCISCO. QUITO - ECUADOR
}

Instituto Metropolitano de Patrimonio

\section{Resumen}

La iglesia de San Francisco es un símbolo cultural y religioso del Centro Histórico, sus obras sirven de base para el Plan de Gestión Integral, en la eliminación de humedades y en los bienes muebles de la basílica principal, con un aporte cercano al millón de dólares, con base en estudios de 2010. Se sometieron los murales a estudios micro y macro, para obtener información histórica del estado de conservación, para efectuar limpieza y retoque de pintura cuando sea necesaria la intervención, evitando en lo posible los retoques. El saneamiento de humedades producidas por tumbas, así como por el sistema de drenaje que afecta, a la vez, a la mampostería. La intervención se da en el convento de San Carlos, realizando una ventilación de las tumbas, arreglo de baterías sanitarias. Se han encontrado claraboyas de ladrillo, intervenciones hechas en el siglo XVI.

Palabras clave: Centro, histórico, limpieza, retoque, humedad, pintura, tumbas.

\begin{abstract}
The church of Saint Francis is a cultural and religious symbol of the Historical Center, and its artworks are the basis for the Integral Management Plan, in which between its activities had the removing of moisture from the main basilica and the restoration of its chattels, with a contribution of one million dollars, with studies since 2010. The murals were undergone to micro and macro studies, in order to obtain historical information about their condition, then the mural paintings were undergone to cleaning and color reintegration color whenever it was needed, trying to avoid color reintegration when it was possible. Also was removed the moisture from the graves and also from the drainage system that was affecting the masonry. The intervention occurs in the convent of San Carlos, performing the ventilation of the graves and repairing the sanitary batteries. Brick skylights were found, interventions held in the sixteenth century.
\end{abstract}

Keywords: Center, historical, cleaning, retouching, moisture, paint, tombs. 
"La restauración es el momento metodológico del reconocimiento de la obra de arte en su consistencia física y su doble polaridad estética e histórica, con miras a su transmisión al futuro"

Cesare Brandi

\section{Antecedentes}

La basílica principal del Convento Máximo de San Francisco Quito (Ecuador) es un centro simbólico cultural y religioso del centro histórico, internamente alberga obras artísticas representativas de la Escuela Barroca de Quito, las que se encuentran en mal estado de conservación según el diagnóstico técnico realizado como parte de los estudios que sirvieron de base para la formulación del Plan de Gestión Integral. Dicho plan tiene el apoyo de varias instituciones públicas. El Municipio Metropolitano de Quito, a través del IMP ha iniciado su apoyo con la intervención en la arquitectura con la eliminación de humedades y en los bienes muebles de la basílica principal (pintura mural, retablos, pintura de caballete, escultura), con un aporte aproximado al millón de dólares. Cabe señalar que en el caso de los bienes muebles, estos no habían sido intervenidos anteriormente, circunstancia que facilitó el trabajo de los restauradores.

La intervención del Instituto Metropolitano de Patrimonio, tanto en la arquitectura como en los bienes muebles, partió de la utilización de información secundaria y de constatación en obra. Para los bienes muebles se siguió la orientación constante en los estudios realizados por el equipo técnico liderado por la restauradora Maria Galeotti el año 2010, apoyado por estudios históricos-iconográficos, estado de conservación de los bienes de acuerdo a su soporte, y las propuestas técnicas y económicas de intervención.

Y para la intervención en la arquitectura de los estudios realizados por los técnicos del IMP y de los hallazgos de la investigación arqueológica que acompañaron al proceso de intervención a lo largo de 2014.

Luego de la actualización de la propuesta y del proceso de contratación definida en las normas de contratación pública, la ejecución de los trabajos la realiza un grupo interdisciplinario con el acompañamiento y seguimiento del IMP, del INPC, y la orden franciscana.

\section{Descripción}

La planta arquitectónica de la basílica es de cruz latina conformada por tres naves. En el ábside se encuentra el altar principal y en las naves se ubican capillas (ocho en total) con sus respectivos altares.

Los muros de la nave central, los intradós de los arcos, los pilares; tienen revestimientos con talla dorada y policromada, así como lienzos y esculturas ricamente decoradas con chinescos.

La cubierta de la nave lateral norte, tiene seis cupulines con sus respectivas linternas por donde ingresa luz que ilumina a los retablos. Estos últimos son decorados con pan de oro y policromías destacándose figuras geométricas, complementadas con esculturas de magnifica manufactura con encarnes realistas y decoraciones en estofado y chinescos. 
La estructura arquitectónica de los retablos de San Antonio de Padua, San Martin de Porres, Virgen del Quinche, y Virgen de la Nube son de tres calles y tres cuerpos, mientras el retablo del señor de la Bofetada es de una sola calle y dos cuerpos con remate, y el retablo del señor de la Columna de un cuerpo y una calle se encuentra empotrado en el muro.

En el ingreso principal hasta el quinto retablo, en el intradós de los arcos se encuentran decoraciones murales con representaciones de mártires franciscanos y en los muros de piedra, juntas doradas, a excepción del muro de la fachada, misma que al interior se encuentra cubierto de enlucido imitando piedra dando la intención de continuidad del material, diferenciándose porque las juntas no tienen dorado.

En la parte inferior del muro de la nave norte, el zócalo simula a marmoleado con decoraciones geométricas a manera de cornisas.

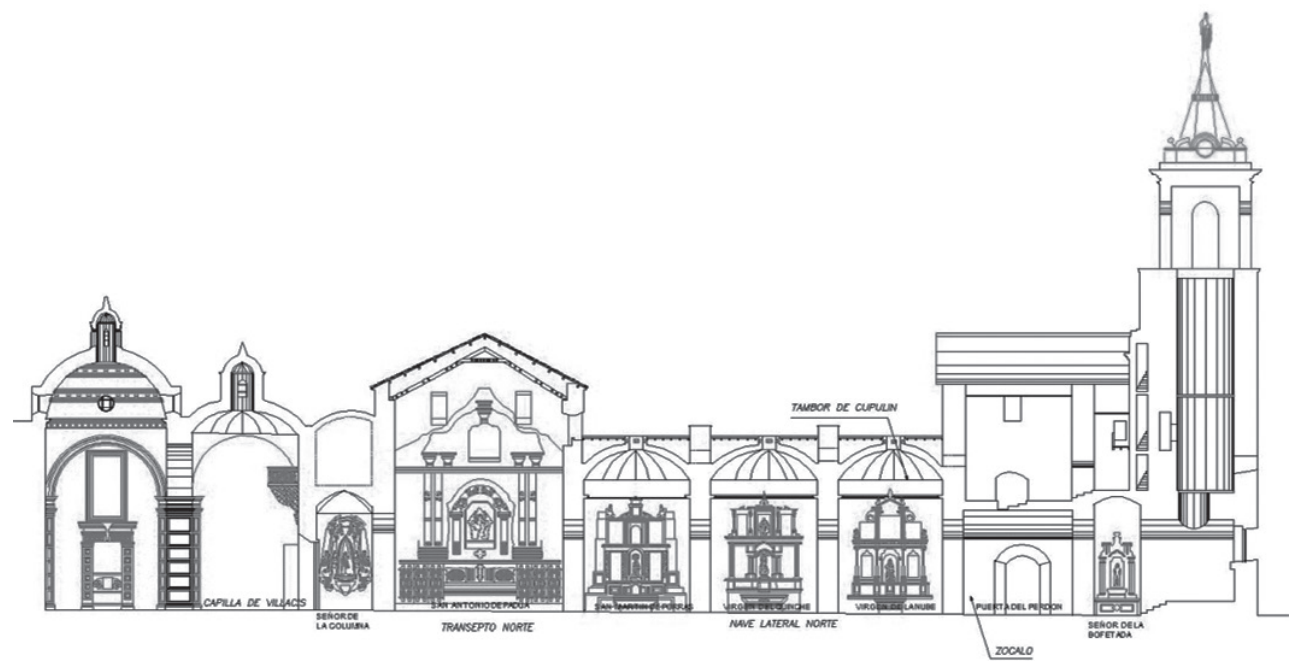

\section{Acercamiento Histórico}

Según los datos de la investigadora Susan Webster entre 1651-1755 se realizaron las decoraciones de la basílica por Fray Jodoco (inscripción del muro oriental de la portería $)^{182}$. La decoración interna “... responde a los mensajes doctrinales, transformando a la ... en un libro ilustrado a través de las pinturas, esculturas, y tallas... " 183; bajo los cánones que dictaminó el concilio de Trento.

En 1647 hubo una marcada intervención de reedificación, que conllevó a la reubicación de altares y retablos, evidenciada por la alteración decorativa e iconográfica, producto, no solo de los deterioros ocurridos en los terremotos de 1775 y 1868; sino por la dinámica cambiante de advocaciones que mutilaron y alteraron muchos elementos.

En el siglo XX con la intervención de instituciones públicas y con la cooperación española se inicia un proceso de intervención importante en el conjunto

182 Webster, 2012.

183 Sevilla, Morán, Pérez, \& Moreno, 2010. 
conventual, anotándose las que tienen relación con la basílica, entre las más importantes están:

- Intervención del artesonado mudéjar y sillería del coro, trabajos puntuales como consolidación de muros (sismo de 1987. Instituto de Cooperación Iberoamericana (ICI) - Instituto Nacional de Patrimonio Cultural (INPC). El Instituto Nacional de Patrimonio Cultural INPC, como contraparte del convenio aporta técnicos funcionarios del INPC en las tareas de coordinación y apoyo técnico a más de los servicios de laboratorio.

- Fondo de Salvamento del Municipio de Quito (Fonsal) ${ }^{184}$

1987.- Aporta técnica y económicamente en obras urgentes, estudio histórico, estudio arqueológico de la basílica, intervención en el atrio y áreas anexas.

2003.- Estudios: Restauración y consolidación del artesonado, cubiertas y cúpulas.

2005.- Estudio y evaluación de los bienes muebles de la basílica.

2007-2008.- Intervención en cubiertas, cúpulas y artesonado barroco de la nave central y mudéjar del crucero.

2008-2009.- Rehabilitación del piso de madera de la basílica.

2010-2011.- Restauracion de 140 esculturas policromadas de la basílica y retablo mayor. Lienzos y elementos de plata, parte del retablo mayor.

2011.- Se interviene en la fachada pétrea y la puerta principal de la basílica.

\section{Bienes muebles}

\section{Estado previo a la intervención ${ }^{185}$}

\section{Retablos:}

Cada retablo cuenta con un estudio exhaustivo de materiales de soporte y base de preparación, y en la fase de intervención se comprobó su estratigrafía encontrándose varias sobrepinturas, a excepción del retablo de San Antonio de Padua que es totalmente dorado.

Los deterioros en general se ubican en deformaciones, fracturas, defectos en las uniones, pérdidas de tallas y soporte; la madera presentaba ataque de xilófagos, reparaciones con material incompatible como es el uso de clavos industriales que se encontraban oxidados, amarres improvisados de alambre. La lectura estética estaba alterada, empobreciendo su real valor, debido a que las decoraciones se encontraban ocultas bajo varias capas de repintes de por lo menos tres épocas, con pintura esmalte crema y en los dorados, purpurina; también existían zonas 
de lagunas de policromía. En general presentaban en sus superficies una acumulación considerable de polvo ligero y graso así como en zonas inferiores se halló gran cantidad de cera.

En el artesonado del sotocoro se encontró que en las uniones se había colocado lienzo que presentaba problemas de adherencia a la madera, así como el estuco aplicado en los lienzos tenían una gran cantidad de fisuras y lagunas producto de la descohesión del estuco al lienzo.

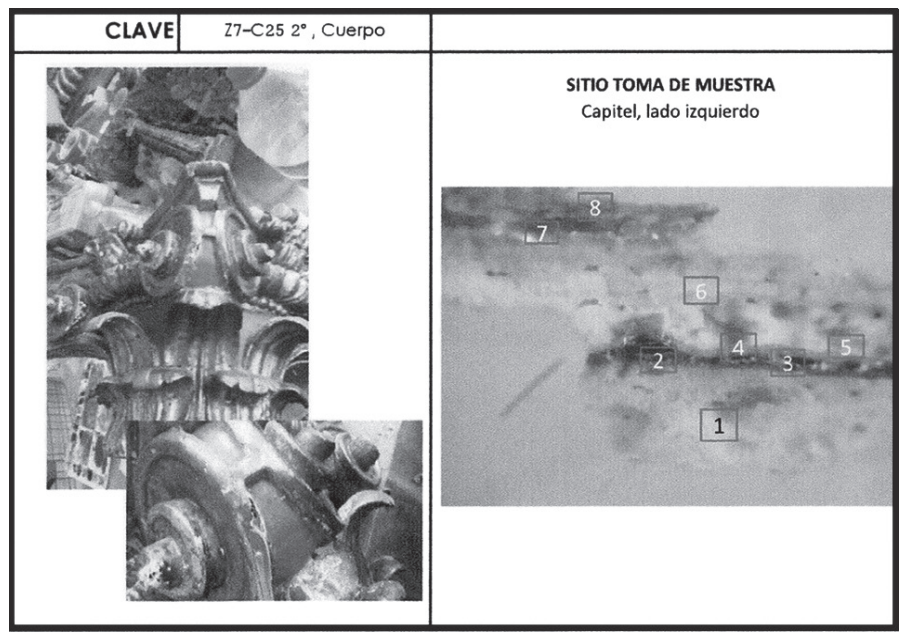

\section{Pintura mural:}

Muchos de los problemas del deterioro están relacionados con la condición arquitectónica y la evolución y/o transformación que tuvo la basílica. Los principales se focalizan en la presencia de humedad por capilaridad que ocasiona migración de sales, con la consecuente exfoliación de estratos.

Las intervenciones realizadas en los cupulines con encalamiento, no dejaron vestigio alguno de decoración anterior. La decoración del tambor fue eliminada, y la presencia de humedad provocó que la capa pictórica como el pan de oro se exfolie y se pulverice.

Las consecutivas reparaciones realizadas sobre la pintura muraria han contribuido al menoscabo de la decoración, tal es el caso de la aplicación de revoques con mortero inadecuado, tanto por su composición (cemento), como por su aplicación poco prolija al sobreponerse en la superficie original, todo esto ha originado varios desprendimientos, y abolsados, ahondado por la indolencia con la que por mucho tiempo el templo no contó con un plan de mantenimiento preventivo y de rutina.

La falta de mantenimiento, adicionalmente trajo la acumulación de polvo graso (mugre) que sumado con el depósito de hollín trasformó los tonos de la policromía y la infestación microbiológica en alto grado.

Previa a la intervención se realizaron toma de muestras y análisis de laboratorio, para completar información del estudio existente, proveniente de lugares donde no se tenían datos certeros. 
De los análisis de laboratorio se obtuvieron los siguientes resultados:

- El soporte de las muestras tomadas es de ladrillo,

- La base de preparación primaria es de sulfato de calcio,

- Los pigmentos de la primera decoración son aglutinados con cal, luego en capas sobrepuestas los pigmentos se aglutinan con aceite, así como también se encontró oleo en la capa pictórica más contemporánea.

- En la generalidad hubo 5 capas de cal como sobre pintura.

- En el resultado del Querubín 5, capulín $\mathrm{N}^{\circ} 8$, se encontró pigmento color negro carbón, planteándose 2 hipótesis, una que fue base etilo bol para pan de plata, o que existió un querubín color negro. No se cuenta con argumentos verificables para inclinarse por alguna de ellas.

Y como conclusión se tiene que las evidencias físicas, muestran que la basílica tuvo tres momentos importantes de decoración muraría, que se indica en el cuadro que sigue:

\begin{tabular}{|l|l|l|}
\hline \multicolumn{3}{|c|}{$\begin{array}{l}\text { EPOCAS DECORATIVAS MURARIAS NAVE NORTE DE } \\
\text { LA BASILICA DE SAN FRANCISCO }\end{array}$} \\
\hline Zócalos & $\begin{array}{l}\text { técnica pictórica de } \\
\text { marmoleado, al oleo }\end{array}$ & $\begin{array}{l}\text { más } \\
\text { cercana a } \\
\text { nuestros } \\
\text { días }\end{array}$ \\
\hline Puerta del perdón & $\begin{array}{l}\text { Decoración de roleos y } \\
\text { floral, aglutinado con } \\
\text { temple graso. }\end{array}$ & Intermedia. \\
\hline $\begin{array}{l}\text { paramentos y } \\
\text { tambores de cupulines }\end{array}$ & $\begin{array}{l}\text { decoración floral, dorados y } \\
\text { encarnes de querubines, } \\
\text { temple magro }\end{array}$ & primigenia \\
\hline
\end{tabular}

\section{Criterios de intervención}

La intervención en bienes culturales está normada por principios éticos y deontológicos inherentes a la restauración de los bienes patrimoniales que garantiza su permanencia conservando la autenticidad y originalidad, y en el caso que nos ocupa, como bienes religiosos que aun conservan su función y uso para el culto. Las decisiones tomadas en la ejecución de la obra, responde a las condiciones en que se encuentran las obras, y al análisis y consenso del grupo interdisciplinario e interinstitucional que actúa como comité de seguimiento.

Los criterios asumidos son:

- Para evitar un falso histórico, la reconstrucción de faltantes solo se la realizará en casos que afecten la integridad de la obra, o impidan su correcta lectura.

- Para no alterar la concepción estética de la época histórica a la que pertenece, se eliminan los repintes, contando siempre con el respectivo análisis que permita valorar la intervención y tomar decisiones.

- Las intervenciones serán claramente identificables con el uso de materiales y técnicas compatibles con los originales. 


\section{Intervención}

\section{A. Retablos ${ }^{186}$}

Se partió con la realización de calas constructivas para catar el estado de conservación de las estructuras; encontrándose que estaban con un alto grado de deterioro; y al no ser posible la intervención in situ, debido a la falta de espacio entre el muro y el mueble, se procedió a su desmontaje, previamente codificado y gráficamente registrado. (Registro fotográfico y levantamiento gráfico).

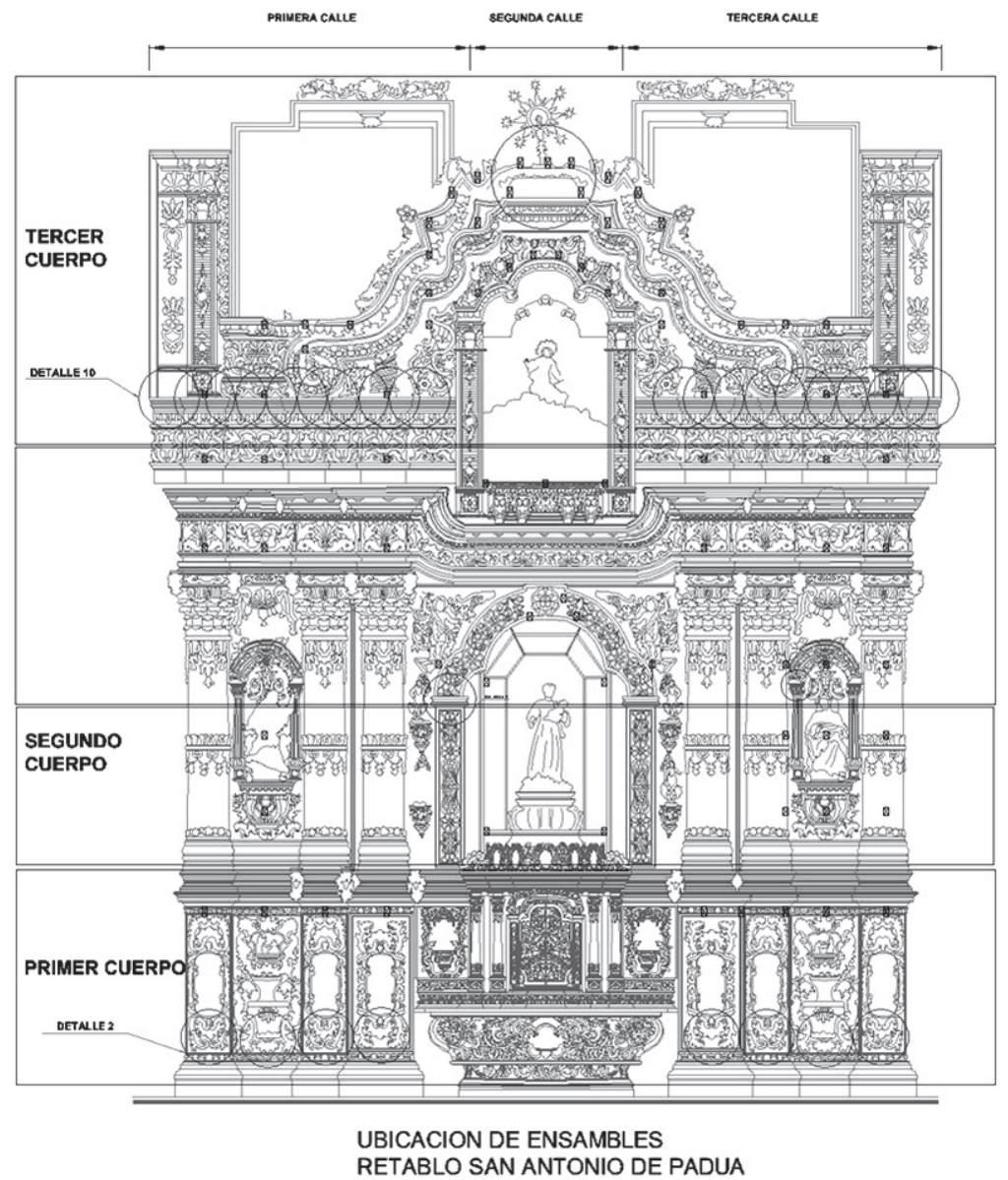

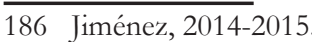




\section{TIPOS DE ENSAMBLES RETABLO Z-10 SAN ANTONIO DE PADUA}

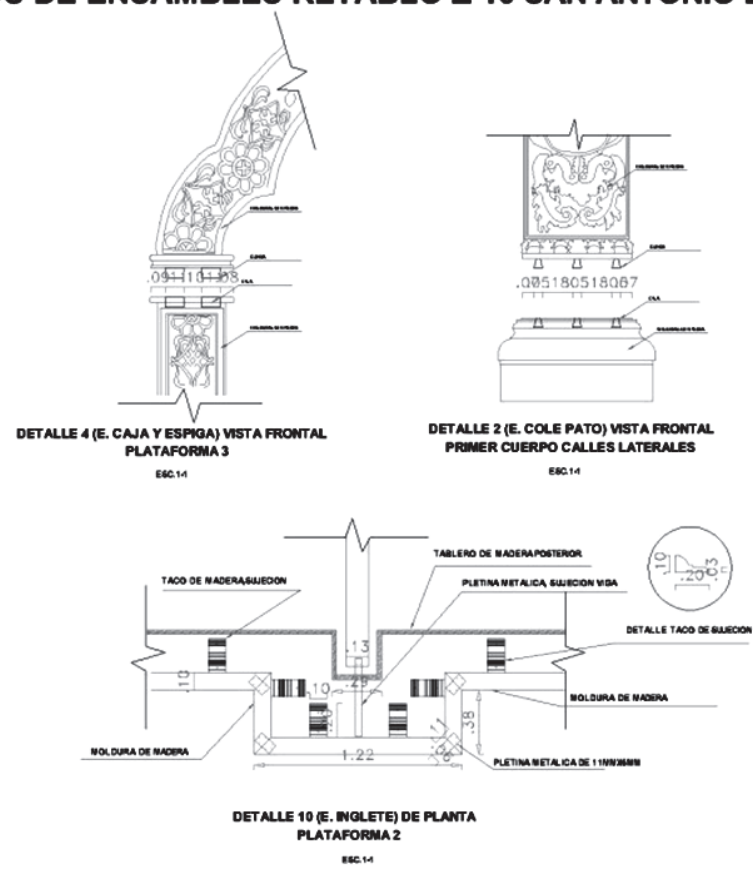

Las piezas se sometieron a una limpieza profunda eliminando polvo y rebabas de colas y estucos, para la desinfección se aplicó preservantes con contenidos fungicidas, bactericidas e insecticidas. Para devolver las características mecánicas de la madera debilitada por los ataques de xilófagos, y una vez preservada la madera, tanto la antigua como las nuevas usadas en injertos y restituciones, se aplicó resina acrílica como consolidante.

La restructuración y reforzamiento estructural se realizó con toledanas y corbatines. En los ensambles con encolados y colocación de tarugos, eliminando previamente elementos extraños como clavos que afectan a la madera. Las tallas fueron restituidas únicamente cuando por su dimensión se requería.

En el anverso de las piezas se realizó una limpieza superficial, remoción de ceras y polvo graso, y con base a los análisis de laboratorio se identificaron al menos 6 capas de revestimientos, 3 que correspondían a bases de preparación, una de imprimación, pinturas y barnices. La decisión de removerlas exigió de mucha precisión para evitar la remoción de las capas originales, se usó para el efecto ácido acético y vapor de agua.

La restitución de lagunas de base de preparación se la realizó con tecnologías tradicionales usando estucos preparados con cola de conejo, y para no interrumpir la lectura estética del mueble, se reintegró color en las lagunas estrictamente necesarias.

Para el montaje, se trataron los muros consolidándolos, fijando enlucidos, y en los puntos de empotramiento la colocación de pintura asfáltica en las vigas para evitar pudrición de la madera. Antes de colocar los puntos de sujeción definitivos 
se hizo un pre montaje de cada cuerpo de los retablos con la finalidad de verificar los niveles.

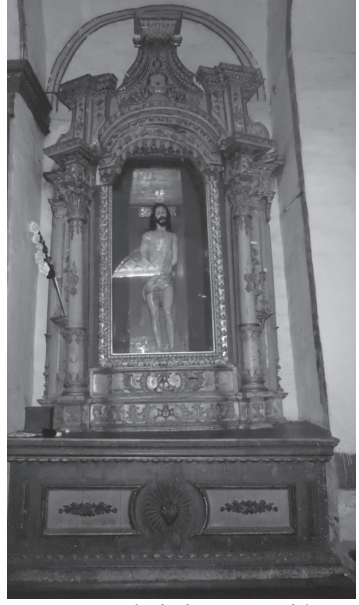

Antes de la intervención

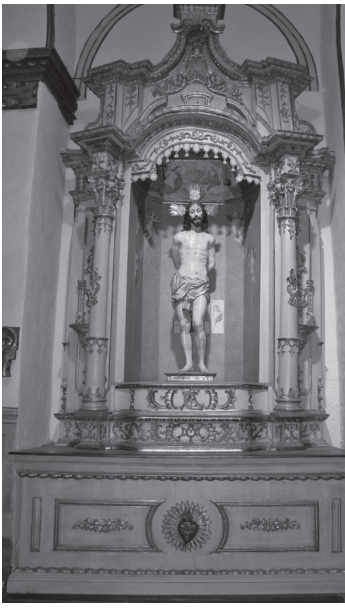

Después de la intervención
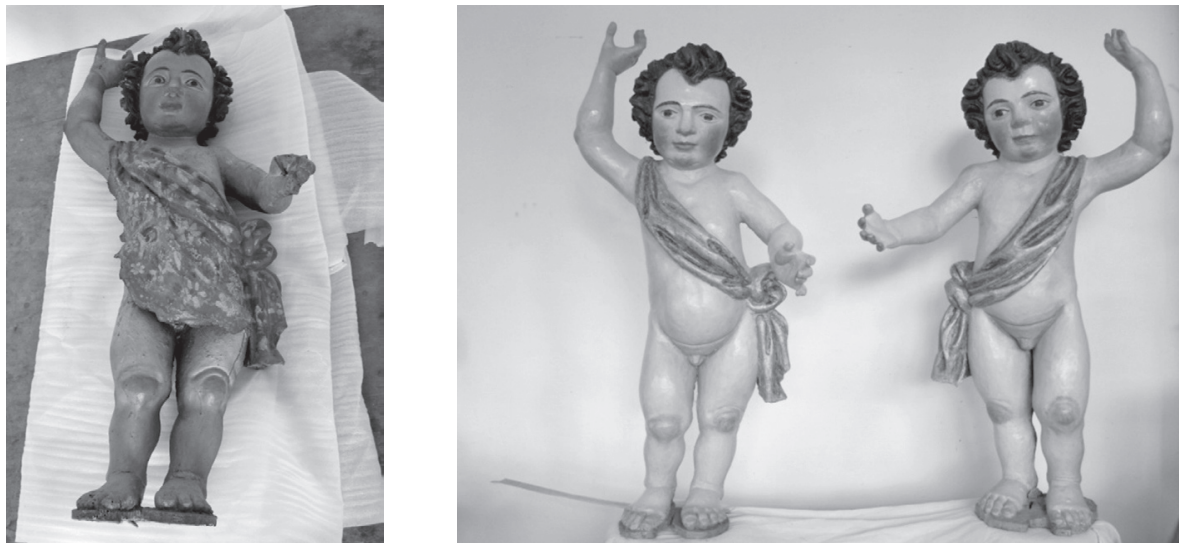

\section{B. Pintura mural ${ }^{187}$}

Con la finalidad de contar con información histórica sobre las intervenciones realizadas (alteraciones, adiciones y restauraciones); y conocer el material de soporte, capas superpuestas; se realizaron calas de prospección las que se sometieron a estudios de escala micro y macro, cuyos resultados aportaron la conformación del diagnóstico del estado de conservación y a la propuesta de intervención.

La intervención partió de una desinfección microbiológica para controlar la proliferación, en las superficies murarias, seguida de limpieza superficial, y en los zócalos la eliminación de polvo graso, cera y hollín acumulado. Adicionalmente se eliminaron los repintes aplicados puntualmente sobre la pintura de los zócalos, así como morteros inadecuados y revoques. En la restitución se usó mortero de cal con dosificación 6:2:1 (arena, cal, puzolana). 
En los tambores de los cupulines al eliminar la pintura de cal se obtuvieron vestigios de pintura decorativa primigenia los que se quedaron expuestos como testigos de la evolución histórica del monumento.

En ciertas áreas que presentaban sales solubles, se las eliminaron con papetas de $\mathrm{pH}$ neutro y agua desmineralizada, y para las insolubles de origen de nitratos, se las eliminó manualmente.

La consolidación superficial y profunda se la realizó con adhesivo sintético, enriquecido con carga en los casos de oquedades mayores. Para el tratamiento de grietas se colocó segmentos de mangueras equidistantes a lo largo de la misma, en las que se inyectó a presión, mortero expansivo.

Las lagunas de base de preparación fueron reintegradas con carbonato de calcio micronizado, cuidando de conservar las irregularidades aledañas y de no invadir la capa pictórica.

En la reintegración de color y con la finalidad de diferenciarla del original, se utilizó un tono más bajo.

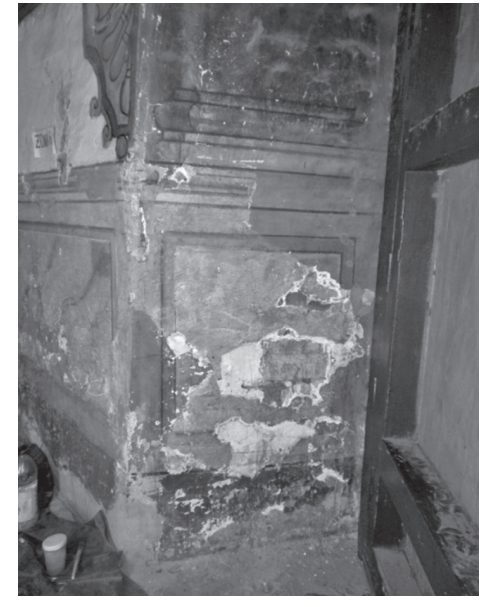

Antes de la intervención

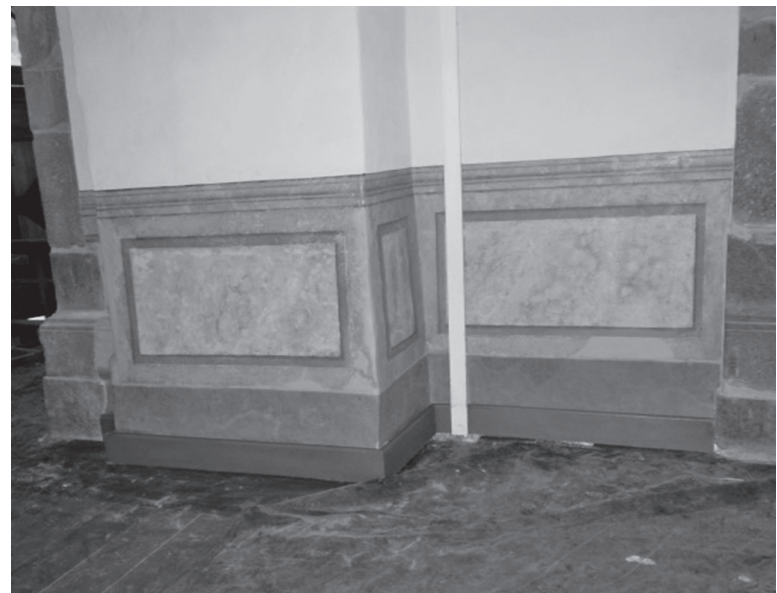

Después de la intervención

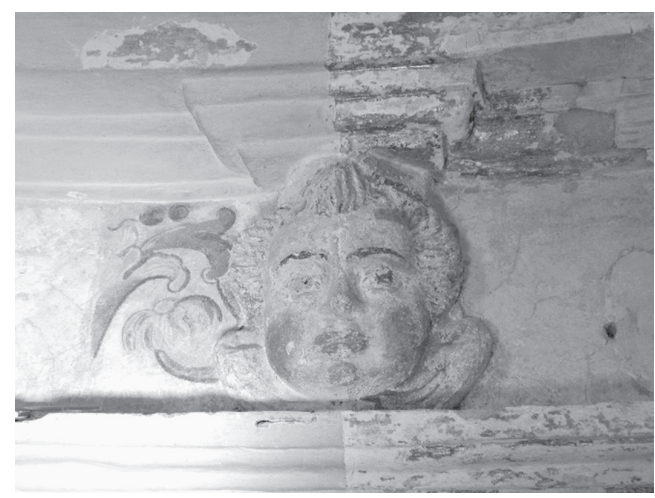

Mascarón 


\section{Saneamiento de humedades en la nave sur de la Basílica de San Francisco}

A finales del 2014 se inician los trabajos de saneamiento de humedades detectados en el muro sur, en el que se implantan cementerios y la capilla del Pilar, espacios afectados por humedad, patología que pone en peligro a otras áreas donde se encuentran bienes muebles de invalorable valor histórico - religioso y artístico.

A pesar de innumerables intervenciones realizadas a lo largo de la historia para el control de filtraciones, fugas y niveles freáticos, aun no se ha podido eliminar y canalizar las humedades, desconociéndose las causas y su origen. Se aduce que quizás la presencia de quebradas, rellenos y las diferentes características estratigráficas del área en el que se asienta el conjunto conventual podrían ser las que incidirían en las filtraciones a las estructuras arquitectónicas, tanto en cimientos como mamposterías, con la consecuente afectación a bienes muebles como se anotó.

\section{Diagnóstico}

El muro sur de la Capilla del Pilar se encuentra en malas condiciones, los enlucidos y la pintura mural decorativa -en un alto porcentaje- por presencia de sales y moho, están desprendidas, notándose grandes lagunas, con la pérdida de las decoraciones de la capilla, y del cielo raso helicoidal. La capilla se encuentra limitada por el sur y el este con criptas, al occidente por la sacristía y al norte por el presbiterio del altar mayor.

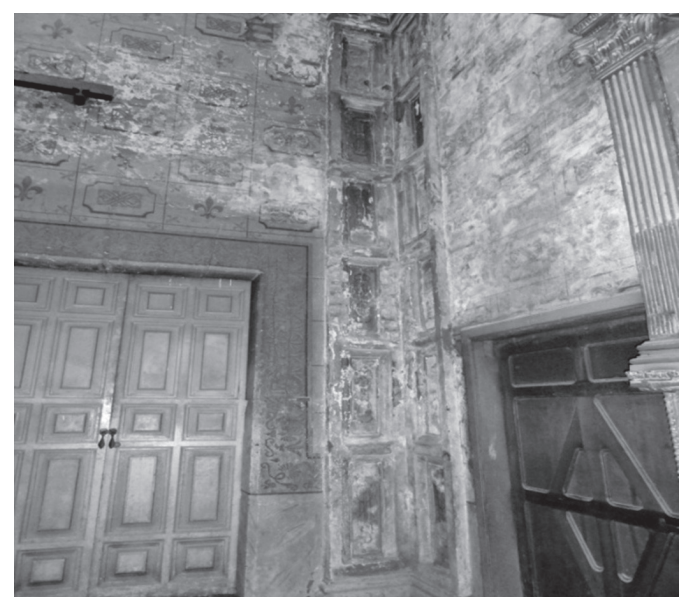

Capilla Virgen del Pilar

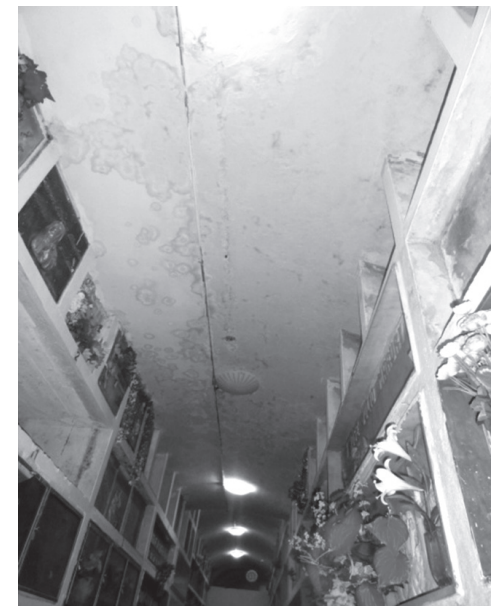

Criptas

Las criptas, concentran un alto grado de humedad debido a que no disponen de ventilación y posiblemente por la migración de agua proveniente de los jardines, de la canalización de aguas lluvias y servicios higiénicos del Convento de San Carlos, edificación con la que colinda el conjunto conventual de San Francisco.

\section{Intervención}

La intervención se concentra en el convento de San Carlos, específicamente en la crujía norte del claustro, en la que se realizaron varias prospecciones para veri- 
ficar el estado de conservación de los bajantes y canales de conducción de aguas a nivel de piso, prospecciones que condujeron a hallazgos importantes como la existencia de estructuras arquitectónicas de gran valor, conformada por arcos y bóvedas, canales, pisos, traga luces y ductos de ventilación, junto con la identificación de algunas de las causas que producen la humedad, siendo las de mayor incidencia el desfogue de las aguas lluvias directamente en el terreno, afectando a toda la mampostería de las criptas e iglesia.

Otra de las causas es el desgaste del material de la canalización de cemento localizada bajo tierra, que por el tiempo y la corrosión afectó a los mampuestos de ladrillo; así como la jardinería existente en el claustro, junto con las baterías sanitarias existentes (plantas 1 y 2) que por falta de mantenimiento, sus instalaciones hidro-sanitarias se encontraban deterioradas y rotas, todas estas se constituyeron en focos de humedad adicional a las anotadas.

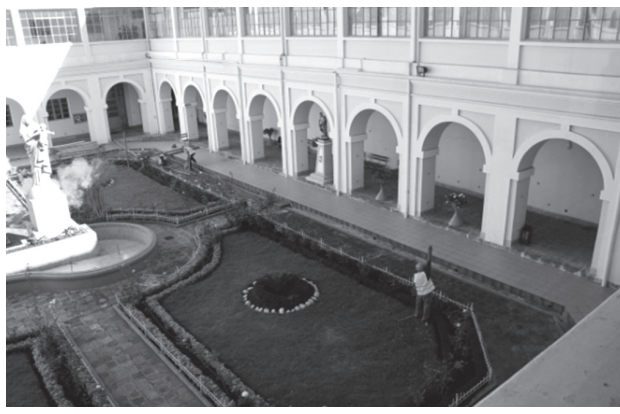

Convento de San Carlos frente de intervención

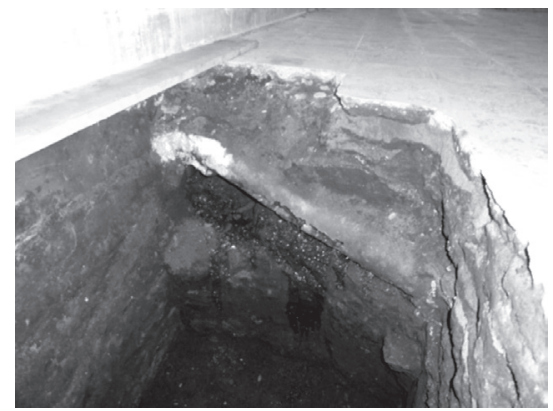

Tuberia rota, filtraciones de agua

Lo anotado llevó a que se realicen trabajos de conducción y desalojo de aguas lluvia y negras, la clausura de los servicios higiénicos, y en los jardines, instalar un sistema de drenes en espina de pez, para la captación y desalojo de aguas lluvia, mientras que en las baterías sanitarias se procedió al retiro de todas las tuberías de agua potable y desalojo de aguas negras, para ser sustituidas por otras de mejor calidad cobre y de presión.

Los hallazgos del sistema de ventilación sobre las criptas que se encuentran detrás de la capilla del Pilar y de la sacristía de la iglesia fueron habilitados (4 u) lo que ha permitido que los muros de este sector estén en pleno proceso de disminución de las humedades existentes.

Las soluciones técnicas adoptadas e institucionales han mantenidos como criterio el máximo respeto a la autenticidad e integridad que exige el proceso de intervención en un monumento de la importancia de San Francisco.

Para concluir la intervención, queda pendiente la decisión de la comunidad franciscana sobre el retiro de las tumbas de las criptas que se encuentran detrás de la nave lateral sur de la iglesia con el fin de mejorar el proceso de eliminación de las humedades, cuya medición es la que sigue:

Porcentaje de humedad en muros:

- Nivel entre 0,00 e 1,50 m la humedad disminuye $4 \%$, 
- Nivel 3,00 m la humedad disminuye 2\%

- Nivel. $5 \mathrm{~m}$ la humedad no disminuye y se mantiene en 100\%

Adicionalmente, en un futuro se podría retirar los tapiados de los vanos encontrados que ayudarían a mejorar los niveles de humedad de los espacios y definir los usos para visita.

\section{Hallazgos}

Con el apoyo de una arqueóloga, las excavaciones realizadas en una profundidad variable entre $1 \mathrm{~m}$ y $5 \mathrm{~m}$, arrojaron información valiosa relacionada con intervenciones realizadas desde el siglo XVI hasta el XIX. Entre los hallazgos están los sistemas constructivos utilizados para la ventilación y la iluminación.

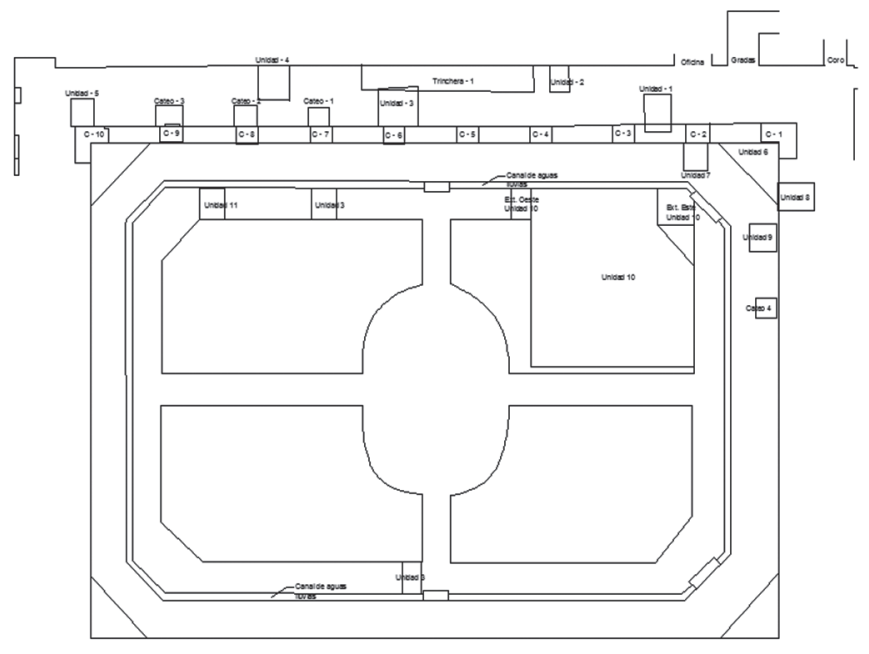

Ubicación de las unidades de excavacion

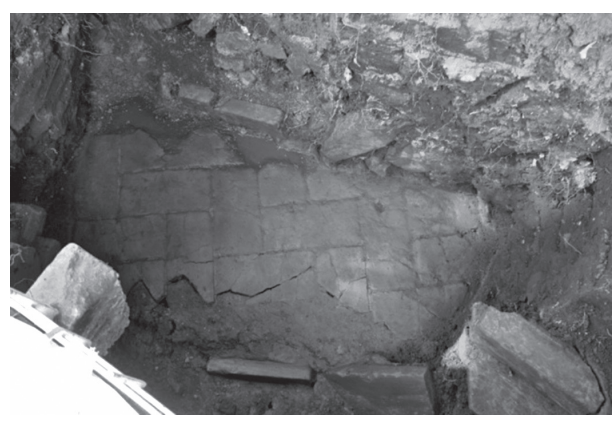

Pisos de ladrillo pastelero (unidad 10)

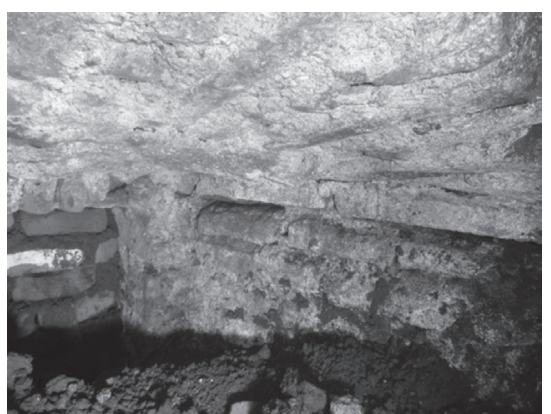

Vano tapiado, ingreso a las criptas que estan detrás de la nave lateral sur de la iglesia (unidad 2) 


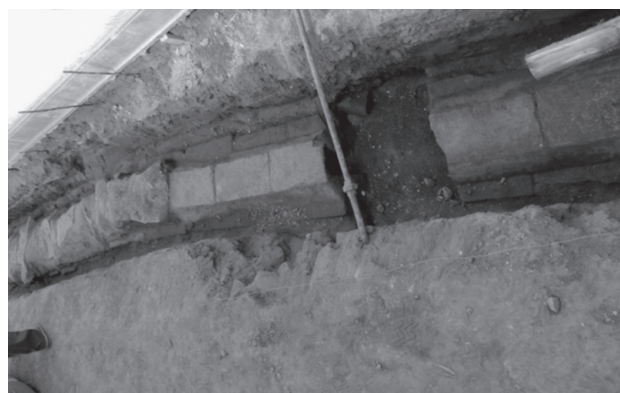

Canales de aguas lluvia (trinchera 1)

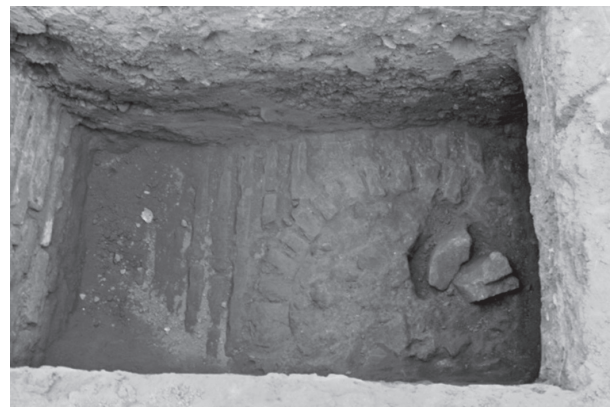

Lucernario tapiado y bóveda de la cripta que está detrás de la capilla de la Virgen del Pilar. (Unidad 4)

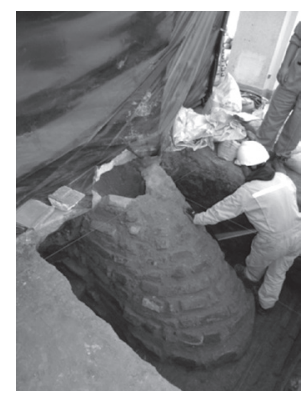

Ducto de ventilación sobre las criptas que estan detrás de la capilla de la Virgen del Pilar (cateo 1)

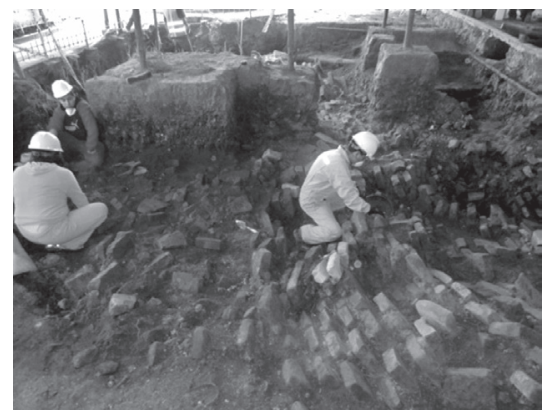

Posible arco y bóveda colapsada (unidad10)

Los hallazgos dan cuenta que la disposición de elementos arquitectónicos y espaciales corresponden a dos secuencias constructivas. Uno al que corresponde los espacios abovedados construidos en ladrillo con claraboyas, modificadas posteriormente con mechinales o huecos colocados a los costados para proveer de ventilación y luz a los espacios que hoy forman el cementerio ubicado al costado de la Capilla de la virgen del Pilar.

El otro corresponde a un sistema de arcos que podría haber sido una crujía del claustro anterior al existente, el que se dibuja desplomado en el jardín del claustro, así como canales de evacuación de aguas lluvias y de ventilación en dirección a la calle Bolívar, arcos de descarga que conectaban el interior del convento a través de una posible puerta que ahora permanece sellada.

Estos hallazgos llevan a reflexiones sobre la historia de la ciudad y su relación con los constantes procesos sísmicos que ha sufrido y que han marcado en algunos casos la desaparición de elementos o la reconstrucción de los mismos; también permite plantearse hipótesis relacionadas con la vida y condiciones del convento y como podrían haber sido las edificaciones de haber existido en este sitio. 


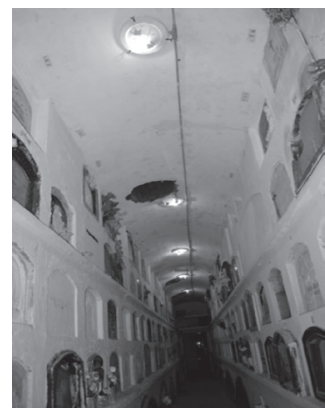

Bóveda cripta

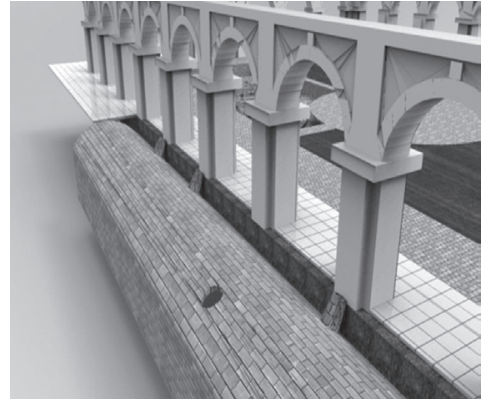

Reconstruccion bipotética de bóveda

\section{Bibliografía}

\section{Bienes muebles}

Cevallos, L. (2015). Resultados de análisis de laboratorio de bienes patrimoniales Nave Norte de la Basilica de San Francisco. Quito: IMP.

Galeotti, M. (2010). Estudio Integral de los bienes muebles de la Basílica de San Francisco. Quito: FONSAL.

Guama, E. (2014-2015). Informes de obra de la intervención de la pintura mural de la nave norte de la basílica de San Francisco. Quito: IMP.

Jiménez, M. (2014-2015). Informes de obra de la intervención de retablos de la nave norte de la basílica de San Francisco. Quito: IMP.

Sevilla, Morán, Pérez, \& Moreno, \&. (2010). Estudio histórico e iconográfico de los bienes muebles de la basilica de San Francisco. Quito: FONSAL.

Vega, H. (2014). Ayuda Memoria. Quito: Comunidad Franciscana.

Webster, S. (2012). Quito ciudad de maestros en el largo siglo XVII. Quito: Abya-Ayala.

\section{Arquitectura}

Domínguez, Victoria. Informe prospección arqueológica 2015 IMP.

Donoso César, Intervención en cubiertas, cúpulas y artesonado barroco de la nave central y mudéjar del crucero. 2007-2008.

FONSAL, El Fondo de Salvamento del Patrimonio Cultural 1996-2000.

Gento Sanz, Fray Benjamín. (1942), Historia de la obra constructiva de San Francisco de Quito.

IMP Instituto Metropolitano de Patrimonio 2014. Una mirada del 2009 - 2014

Mantilla César, Rehabilitación del piso de madera de la basílica. 2008-2009.

Martínez Fernando, Intervención en la fachada de piedra y puerta principal de la basílica. 2011.

Uría Guadalupe, Intervención saneamiento de humedades. 2014-2015. 